\title{
EDITORIAL
}

\section{Cutting cognitive holes}

Once upon a time, there was a group of farmers who really understood their profession and did a wonderful job. They had a good holistic perception of their professional practice (even if they had never heard of the term "holism") and they know what to do in any situation.

To them came some young academics who pretended - even if they admitted that they had never done any farming - to know how to improve the farming business. They organised a seminar and had a great presentation in which they suggested techniques such as linear, nonlinear, integer and combinatorial ploughing, greedy harrowing, tree search and backtracking, trench \& drown. Furthermore, they knew about many problems even the practising farmers had not yet heard of, such as the travelling sower's problem, the simple and the multiple seed-sack problem, the seed covering problem, the seed partitioning problem, the seed packing problem etc.

The farmers were quite impressed and foresaw a great chance to improve their business remarkably, and they hired the academics. On top of that the expectations in this new academic approach were accompanied by self-doubts of the farmers: "Did we do right doing our profession without academics as yet", they kept asking each other.

Over the years, some technical processes and some isolated operations could indeed be improved. for example, linear ploughing was extremely successful in some of their fields, and tree search as well as backtracking helped them to organise some minor forestry operations. They also had some three or four applications of trench \& drown. Encouraged by such practical successes theory exploded, and cohorts of new academics created multi-criteria ploughing, interior point harvesting, fuzzy seed theory, data envelopment analysis etc.

But as far as their farming as a holistic profession is concerned, the farmers had little support from academia. Fortunately, they had not given up their holistic perception of their professional practice. After some 40 years or so, someone explained the situation as follows: "Your understanding of your profession is holistic, comprehensive, systemic, and your cognitive culture is like a cobweb. What these academics offer is nothing else than replacing some single knots of you cognitive cobweb by highly efficient mechanisms. But, if you followed them, holes would be cut into your cognitive cobweb, and the cobweb would eventually break into pieces. What these academics did not offer, is a real support that reinforces the cognitive cobweb as a whole."

Is this not one of the weaknesses of the OR/MS as well as of the Al community? We prefer to offer techniques for isolated operations instead of giving real support to the managers' cognitive processes. We prefer to offer algorithms for mathematically appealing structures (independent of the reality in the single case) instead of sitting with the problem owners and considering their real concerns.

Would it not be worthwhile to see the purpose of OR/MS and $\mathrm{Al}$ in the design of "cognition support systems"? Should our endeavours not start with the attempt to understand the subjective view of the problem owner - instead of trying to design a pseudo-objective model of our own view? The sophistication of such new kind of OR/MS and AI would be measured in its subjectively perceived cognition support - instead of mathematical elegance. Even if no final working concept of cognition support systems can as yet be offered, why do not large parties of the OR/MS community try to develop concepts and frames for such systems?

by: Prof. Dr. Heiner Muller-Merbach, University of Kaiserslautern. 


\section{A response from Ernest Field}

\section{Inside - Outside?}

Heiner Muller-Merbach's comments highlight for me the division that exists between people who provide OR services from within an organisation and those that operate from outside.

When I formed my first OR unit in a major oil company, servicing the needs of a marketing department, I was also a member of the marketing management team. In addition to my duties as an OR manager, I participated in all the general management activities including company recruitment, strategic planning and budgeting. Thus I was continually involved with my OR clients on many aspects of marketing and general company work, not directly associated with the OR projects. It's my impression that most OR managers of internal OR units would be likewise involved in their clients' business affairs.

Under such conditions it would be difficult for the OR manager to be unaware of the "subjective view of the problem owner", or to fail to appreciate the "holistic perception" that their clients had of their own professional practice. The OR managers would make use of such knowledge in the conduct of the OR projects.

Thus whilst I appreciate the point that Heiner is making and in general support his thesis, I believe the real difficulties in this area lie with those providers of OR services who are denied the opportunity to participate fully in the internal work of the organisation. I would also add that many OR projects are aimed at filling or "darning" holes in the manager's perception of business practice, and their results provide managers with increased understanding of their practices and added value to all their decisions.

\section{Response to Ernest Field's comment "Inside - Outside?"}

\section{OR in the UK is different}

After the first International OR Conference, Oxford 1957, a report was published in "The Economist" (7th September 1957, pp. 784-787) stating: "The American approach to operational research, as was evident at this week's conference at Oxford, differs significantly from the British: the experts from the United States were concerned more with the elaboration of its techniques, and with the study of large working system in all their ramifications, than with the practical case studies and applications British speakers described. It would be pleasing, nationalistically, to infer that here is a branch of science that British industry is applying more fully than American."

Russ Ackoff, 22 years later, stated the difference still existed (Journal of the OR Society, no. 2/79 and 3/79).

My impression is that OR/MSS research, education and practice in most countries are following the American way and that the British way, described by Ernest Field, is still unique.

Therefore, the article in The Economist, Russ Ackoff's papers, Ernest's comments and my IFORS Forum letter should be read in the UK as an encouragement to keep the uniqueness of British OR.

Heiner Muller-Merbach 